\title{
Natural Killer Cells Promote Tissue Injury and Systemic Inflammatory Responses During Fatal Ehrlichia-Induced Toxic Shock-Like Syndrome
}

\author{
Heather L. Stevenson, ${ }^{*}$ Mark D. Estes, ${ }^{\star \dagger \ddagger}$ \\ Nagaraja R. Thirumalapura, ${ }^{*}$ David H. Walker, ${ }^{\star \dagger \ddagger}$ \\ and Nahed Ismail ${ }^{\S}$ \\ From the Department of Pathology, "University of Texas \\ Medical Branch, the Sealy Center for Vaccine Development, ${ }^{\dagger}$ \\ and the Center for Biodefense and Emerging Infectious \\ Diseases, ${ }^{\ddagger}$ Galveston, Texas; and the Departments of \\ Pathology, Microbiology and Immunology, Meharry Medical \\ College, Nashville, Tennessee
}

Human monocytotropic ehrlichiosis is caused by Ebrlichia chaffeensis, a Gram-negative bacterium lacking lipopolysaccharide. We have shown that fatal murine ehrlichiosis is associated with $\mathrm{CD8}^{+} \mathrm{T}$ cell-mediated tissue damage, tumor necrosis factor- $\alpha$, and interleukin (IL)-10 overproduction, and $\mathrm{CD}^{+} \mathrm{Th} 1$ hyporesponsiveness. In this study, we examined the relative contributions of natural killer (NK) and NKT cells in Ebrlichiainduced toxic shock. Lethal ehrlichial infection in wildtype mice induced a decline in NKT cell numbers, and late expansion and migration of activated NK cells to the liver, a main infection site that coincided with development of hepatic injury. The spatial and temporal changes in NK and NKT cells in lethally infected mice correlated with higher NK cell cytotoxic activity, higher expression of cytotoxic molecules such as granzyme $B$, higher production of interferon- $\gamma$ and tumor necrosis factor- $\alpha$, increased hepatic infiltration with $\mathrm{CDB} \alpha \mathrm{CD}_{11}{ }^{+}$dendritic cells and $\mathrm{CD8}^{+} \mathrm{T}$ cells, decreased splenic $\mathrm{CD}^{+} \mathrm{T}$ cells, increased serum concentrations of IL-12p40, IL18, RANTES, and monocyte chemotactic protein-1, and elevated production of IL-18 by liver mononuclear cells compared with nonlethally infected mice. Depletion of NK cells prevented development of severe liver injury, decreased serum levels of interferon- $\gamma$, tumor necrosis factor- $\alpha$, and IL-10, and enhanced bacterial elimination. These data indicate that NK cells promote immunopathology and defective anti-ehrlichial immunity, possibly via decreasing the protective immune response mediated by interferon- $\gamma$ producing $\mathrm{CD} 4^{+}$Th1 and NKT cells. (Am J Pathol 2010, 177:766-776; DOI: 10.2353/ajpath.2010.091110)
Human monocytotropic ehrlichiosis (HME) is an emerging tick-borne and a life threatening illness caused by Ehrlichia chaffeensis, an obligatory intracellular bacterium. $^{1,2}$ HME can manifest as either mild disease with nonspecific flu-like symptoms or severe and fatal disease that presents as toxic shock-like syndrome, multi-organ failure, or adult respiratory distress syndrome. ${ }^{2-6}$ Severe $\mathrm{HME}$ in immunocompetent patients is thought to be due to immune-mediated pathology, which is attributed to severe inflammation in the absence of large quantities of ehrlichiae in the tissues. ${ }^{4}$ Doxycycline treatment is most effective if administered early in the course of illness. ${ }^{1,7}$ The lack of complete understanding of the pathogenic mechanisms of Ehrlichia-induced toxic shock-like syndrome is a major limitation in successful management of these patients. Ehrlichia muris and Ixodes ovatus Ehrlichia (IOE), which are closely related to each other and to $E$. chaffeensis, stimulate protective or pathogenic immune responses, respectively, in C57BL/6 mice. ${ }^{8,9}$ Intradermal (i.d.) and intraperitoneal (i.p.) infection with a high dose of IOE induces mild and fatal disease, respectively. ${ }^{9}$ Using these models, we and others have shown that antigenspecific interferon (IFN)- $\gamma$ producing CD $4^{+}$Th 1 cells and IgG2a antibodies play important roles in protective immunity against Ehrlichia. ${ }^{4,10,11}$ In contrast, fatal murine ehrlichiosis, which recapitulates the pathological and laboratory manifestations of fatal HME is associated with a suppressed or weak CD4 ${ }^{+}$Th1 immune response, marked lymphopenia, high levels of serum tumor necrosis factor (TNF)- $\alpha$ and interleukin (IL)-10, and severe liver

Supported by a grant from the National Institute of Allergy and Infectious Diseases (Al31431 to D.H.W.), and from National Center for Research Resources (5g12RR003032 to N.I.), and a fellowship from the McLaughlin Endowment for Infection and Immunity, University of Texas Medical Branch, Institute for Human Infections and Immunity (N.T).

Accepted for publication April 13, 2010.

Supplemental material for this article can be found on http://ajp. amjpathol.org

Address reprint requests to Nahed Ismail, M.D., Ph.D., D(ABMM), Department of Pathology, and Department of Microbiology and Immunology, Meharry Medical College, 1005 Dr. D. B. Todd Jr. Blvd. Nashville, TN, 37028. E-mail nismail@mmc.edu. 
injury, characteristics consistent with toxic shock syndrome. ${ }^{4,5,12} \beta_{2} \mathrm{~m}^{-1-}$ mice, which are deficient in $\mathrm{CD}^{+} \mathrm{T}$ cells and natural killer T (NKT) cells, are resistant to fatal IOE-induced toxic shock when compared with wild-type and $\mathrm{TAP}^{-1-}$ mice that are deficient in only $\mathrm{CD} 8^{+} \mathrm{T}$ cells, suggesting that $\mathrm{CD}^{+} \mathrm{T}$ cells mediate immunopathology and fatal ehrlichiosis. ${ }^{12}$ Interestingly, absence of NKT cells in CD1d ${ }^{-1-}$ mice did not protect mice from fatal ehrlichiosis even though their absence prevented the development of liver injury and systemic inflammation. ${ }^{13}$ LPS-lacking Ehrlichia can directly stimulate IFN- $\gamma$ production by NKT cells in a CD1 days-dependent, but toll-like receptor 4-independent, manner. ${ }^{14}$ Further studies showed that NKT cells are critical for clearance of the bacterial burden in vivo, which may account for death of CD1d ${ }^{-/-}$ mice following lethal ehrlichial infection. ${ }^{13}$

NK cells are abundant in the liver, able to produce high levels of pro- and anti-inflammatory cytokines, and play an important role in innate immunity to microbial pathogens. ${ }^{15} \mathrm{NK}$ cells contribute to the capacity of $\mathrm{CD}^{+} \mathrm{T}$ cells to produce IFN- $\gamma$ and to lyse Listeria monocytogenes- and Mycobacterium tuberculosis-infected monocytes. ${ }^{16,17}$ Cross talk between NK cells and dendritic cells (DC) is essential for maturation of DC and activation of NK cells. IL-12, IL-15, and IL-18 produced by activated macrophages or mature DC activate cytotoxic NK cells and stimulate their IFN- $\gamma$ production, which in turn promotes the expansion of CD4 ${ }^{+}$Th1 cells. ${ }^{17-24}$ While NK cells play a protective role in some viral infections, NK cells cause hepatocyte apoptosis in models of viral hepatitis. ${ }^{25,26}$

The current study was undertaken to specifically delineate the contributions of NK cells and NKT cells to the immunopathogenesis of Ehrlichia-induced toxic shocklike syndrome using animal models of nonlethal and lethal ehrlichiosis caused by i.d. and i.p inoculation of IOE, respectively. Our data provide a new finding suggesting that NK cells contribute to severe tissue injury and suppressed protective immunity during infection with these LPS-lacking, obligately intracellular bacteria.

\section{Materials and Methods}

\section{Mice, Bacteria, and Doxycycline Treatment}

Age-matched (8 to 12 weeks old) female wild-type C57BL/6 mice were used in all experiments (Jackson Laboratories, Bar Harbor, Maine). A highly virulent Ehrlichia spp. (IOE), originally isolated from Ixodes ovatus ticks in Japan, was used in all experiments. ${ }^{8,27,28}$ Mice were inoculated i.d. or i.p. as previously described ${ }^{9}$ with a high dose $\left(\sim 5 \times 10^{4}\right.$ ehrlichial copies) of IOE and were then sacrificed at different time points postinfection (p.i.). Antibiotic treatment of IOE-infected mice consisted of doxycycline injections $(10 \mathrm{mg} / \mathrm{kg}$ body weight, two injections per day) given i.p. for three consecutive days (early treatment at 1, 2, and 3 days p.i, and late treatment at 5, 6 , and 7 days p.i.)(Supplemental Figure S1, A-C at $h t t p: / /$ ajp.amjpathol.org). Mice were housed in the animal research center at the University of Texas Medical Branch and Meharry Medical College in accordance with the institutional guidelines for animal welfare and monitored daily for signs of illness as previously described. ${ }^{9}$

\section{Flow Cytometry and Intracellular Cytokine Staining}

Analysis of the frequency of different cell subsets in liver and spleen including NK, NKT, CD11 ${ }^{+}$, and CD11 ${ }^{+}$ cells, as well as the measurement of expression of Fas and Granzyme B on splenic and liver mononuclear cells (LMNCs) was performed directly ex vivo. For intracellular cytokine staining, the cells were cultured at a concentration of $5 \times 10^{6}$ cells per well along with irradiated naïve syngeneic spleen cells $\left(5 \times 10^{6}\right.$ per well) as antigen presenting cells. The cells were stimulated in vitro with IOE antigen $(5 \mu \mathrm{g} / \mathrm{ml})$ for 18 hours followed by 4 hours incubation with brefeldin A (BD Biosciences, San Diego, $\mathrm{CA}$ ) and then analyzed by flow cytometry. Positive and negative control wells included cells stimulated with 5 $\mu \mathrm{g} / \mathrm{ml}$ ConA or medium, respectively. Optimal concentrations of the following fluorophore-labeled anti-mouse monoclonal antibodies (BD Pharmingen, San Diego, CA) were used: CD3 (clone 145-2C11), CD11c (clone HL3), CD4 (clone GK1.5), CD8 $\alpha$ (clone 53-6.7), granzyme B (clone 16G6; eBioscience), CD11b (clone M1/70), CD4 (clone RM4-5), CD8 (clone 53-6.7), DX5 (clone 1452C11), NK1.1 (clone PK136), CD19 (clone 1D3), B220 (clone RA3-6B2), IFN- $\gamma$ (clone XMG1.2), TNF- $\alpha$ (clone MP6-XT22), Fas (clone FAS), and corresponding isotype controls. Lymphocyte or monocyte populations were gated based on forward and side-scatter parameters, cells were analyzed using a BD FACSCalibur (BD Immunocytometry Systems, San Jose, CA) flow cytometer, and data were analyzed using FlowJo (Tree Star Inc., Ashland, OR).

\section{Determination of Cytokine Levels in Serum}

The concentrations of IFN- $\gamma$, TNF- $\alpha$, and IL-10 in serum samples were determined by Quantikine enzyme-linked immunosorbent assay (R\&D Systems, Minneapolis, MN) according to the manufacturer's recommendations. Concentrations of several $\mathrm{C}-\mathrm{C}$ chemokines and cytokines in serum were determined by microsphere multiplexed cytokine immunoassays (Bio-Plex Cytokine Assay, Bio-Rad Laboratories, Hercules, CA) following the manufacturer's instructions.

\section{Isolation of LMNCs and Hepatic IL-18 Measurement}

LMNCs were isolated and purified using a modified enzymatic dispersal protocol as described previously. ${ }^{29}$ Hepatocytes were removed by differential centrifugation $(36 \times g)$ for 1 minute at $4^{\circ} \mathrm{C}$, and the final pellet containing LMNCs was resuspended in RPMI 1640 medium containing $10 \%$ fetal calf serum and $1 \%$ HEPES. LMNCs were purified using Lympholyte M (Cedarlane Laboratories, Burlington, NC). LMNCs were stimulated with IOE antigen 
(10 $\mu \mathrm{g} / \mathrm{well})$. Supernatant was collected after 48 hours, and IL-18 levels were measured using an anti-IL-18 enzymelinked immunosorbent assay kit (R\&D Systems) according to the manufacturer's recommendations.

\section{NK Cell Depletion and NK Cytotoxicity Assays}

A nonactivating polyclonal antibody (Ab) against asialoGM1 (Wako Chemicals USA, Inc.) ${ }^{30}$ was used for NK cell depletion. C57BL/6 mice were injected i.p. with $40 \mu$ l of 1: 100 dilution of anti-asialo GM1 Ab, or normal rabbit IgG isotype $\mathrm{Ab}$ on days $-1,2$, and 5 of infection. Depletion of NK cells was approximately 95\% efficient as determined by flow cytometric analysis of the number of $\mathrm{CD}^{-} \mathrm{NK} 1.1^{+}$or $\mathrm{CD}^{-} \mathrm{DX} 5^{+} \mathrm{NK}$ cells in the spleen and liver of depleted mice. Injection of anti-asialo GM1 Ab did not affect the number of $\mathrm{CD} 11 \mathrm{~b}^{+}$monocytes and resulted in $\leq 4 \%$ depletion of $\mathrm{CD} 3^{+} \mathrm{NK} 1.1^{+} \mathrm{NKT}$ cells as determined by flow cytometry (data not shown). The effect of depletion of NK cells on splenocyte cytotoxic activity was examined by a functional assay using YAC-1 target cells (ATCC, Manassas, VA). For NK cell cytotoxicity assays, splenocytes were isolated from lethally or nonlethally infected mice, uninfected controls, and lethally infected mice treated with anti-asialo GM1 or control Ab. Effector spleen cells were cultured with YAC-1 cells at different effector to target cell ratios. Cells were then collected and stained with propidium iodide and 3,3'-dioctadecyloxacarbocyanine (DiOC) using the LIVE/ DEAD Cell-Mediated Cytotoxicity Kit (Molecular Probes, Inc., Eugene, OR) and flow analysis following the manufacturer's recommendations. The percent specific lysis was determined as follows: $100 \times$ (experimental release - spontaneous release)/(maximum release spontaneous release). The percent specific lysis was normalized to the number of NK cells in the spleen.

\section{Ehrlichial Load Determination in Collected Organs by Quantitative Real-Time PCR}

Bacterial burden was measured in different organs using real-time PCR as previously described. ${ }^{9}$ Ehrlichial burdens were determined using an iCycler IQ multicolor real-time detection system (Bio-Rad, Hercules, CA). Primers and probes targeting both E. muris and Ixodes ovatus Ehrlichia dsb (which encodes a thio-disulfide oxidoreductase gene) and host glyceraldehyde-3-phosphate dehydrogenase genes were used as described before. ${ }^{9}$ The comparative cycle threshold method ${ }^{31}$ was used to determine the ehrlichial burdens as previously described. ${ }^{9}$

\section{Histopathology and Terminal Deoxynucleotidyl Transferase-Mediated dUTP Nick-End Labeling (TUNEL) Assays}

Formalin-fixed, paraffin-embedded sections of liver were stained with H\&E. Liver lesions were assessed semiquantitatively by four parameters: hepatocyte damage, number of lesions, size of inflammatory foci, and extent of perivascular inflammation as described before. ${ }^{9}$ TUNEL staining was performed on sections that show apoptotic cell death without focal necrosis as described previously. ${ }^{9}$

\section{Statistical Analysis}

Data were analyzed using SigmaPlot software (SPSS, Chicago, IL), and $P$ values were determined using the Student's two-tailed $t$-test. $P$ values less than 0.01 were considered highly significant, and those less than 0.05 were considered significant. Mouse groups contained three mice unless otherwise indicated, and error bars represent the SD for each group. SE of the mean was used for analysis of combined data from more than one experiment.

\section{Results}

\section{Severe Ehrlichiosis Resulted in a Significant Increase in Hepatic CD8 ${ }^{+} \mathrm{T}$ Cells, But Not $C D 4^{+} T$ Cells, when Compared with Nonlethal Disease}

Our previous studies indicated that fatal Ehrlichia-induced toxic shock-like syndrome is associated with a decreased number of $\mathrm{CD} 4^{+}$Th1 cells and expansion of $\mathrm{CD} 8^{+} \mathrm{T}$ cells. We examined whether migration of $\mathrm{CD} 4^{+} \mathrm{T}$ cells to liver could account for the decreased total number of $\mathrm{CD} 4^{+} \mathrm{T}$ cells, using animal models of mild and severe monocytotropic ehrlichiosis caused by i.d./nonlethal and i.p./lethal inoculation with the same dose of highly virulent IOE, respectively. We chose to examine hepatic immune responses since the liver is the main site of ehrlichial infection and where NK and NKT cells are known to accumulate during other infections. The liver is also the main site of Ehrlichia-mediated tissue injury, which correlates with the marked elevation of liver transaminases in patients with HME. It is also considered the site of deposition of apoptotic $T$ cells in several infectious and noninfectious diseases. ${ }^{32}$ Our data show that the percentage and total number of $\mathrm{CD}^{+}$and $\mathrm{CD}^{+} \mathrm{T}$ cells in the spleen of i.p./lethally infected mice were lower than detected in i.d./nonlethally infected mice (Figure $1 \mathrm{~A}$ and $\mathrm{B}$ ) on day 7 p.i. Both nonlethal and lethal IOE infection resulted in increased percentages and absolute numbers of hepatic $\mathrm{CD}^{+} \mathrm{T}$ cells on day 7 p.i. (Figure 1) compared with uninfected controls. The differences in the numbers of hepatic $\mathrm{CD} 4^{+} \mathrm{T}$ cells were not statistically significant between i.d./nonlethally and i.p./lethally infected mice or uninfected control mice. In contrast, i.p./lethal infection significantly increased the percentage and absolute number of $\mathrm{CD}^{+} \mathrm{T}$ cells in the liver compared with nonlethal infection on day 7 p.i. (Figure 1B). These data suggest that the decreased frequency of splenic $C D 4^{+} \mathrm{T}$ cells, unlike that for splenic $C D 8^{+} \mathrm{T}$ cells, is not due to their migration to the site of infection. 
A
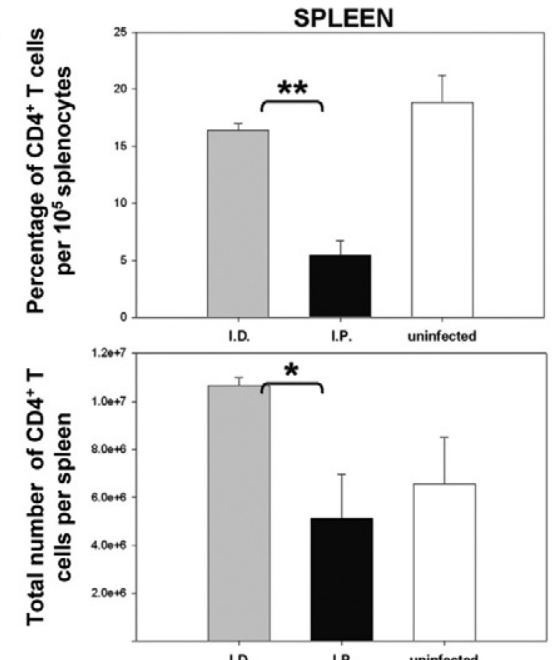

B
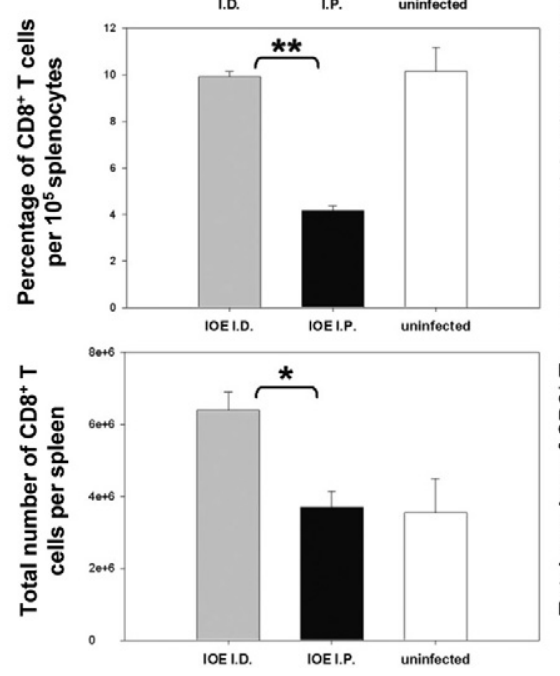
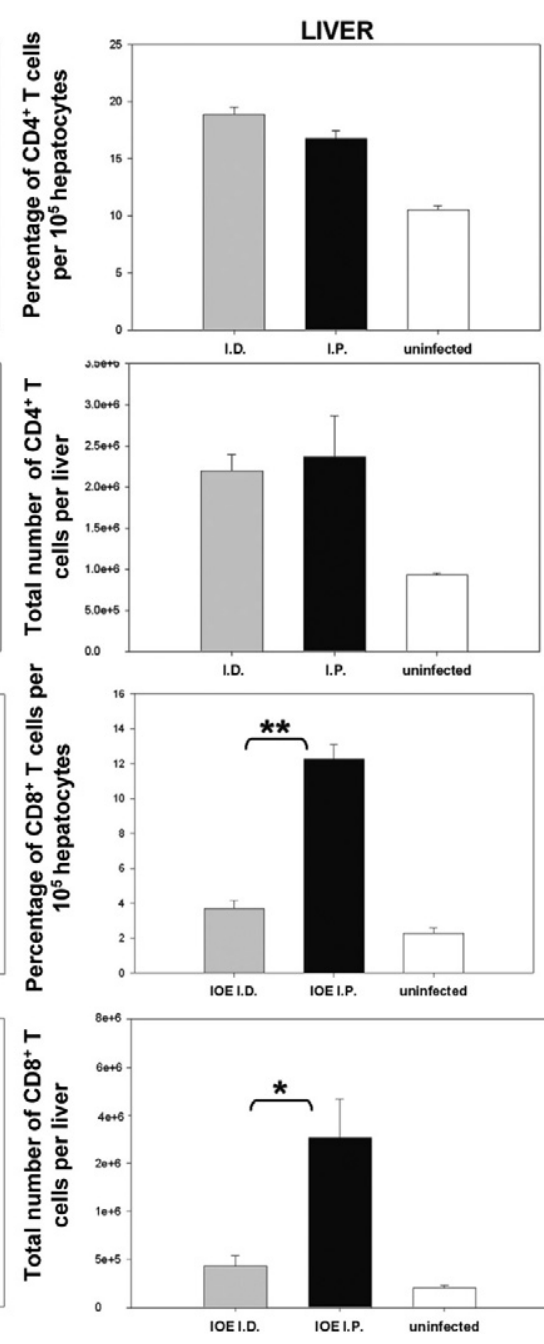
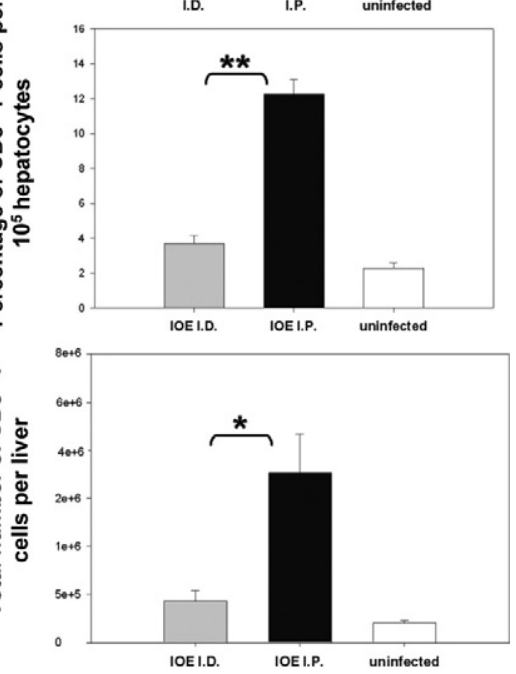

Figure 1. Severe and fatal ehrlichiosis induced a significant reduction of the splenic $\mathrm{CD}^{+} \mathrm{T}$ cel population and a significant expansion of the hepatic $\mathrm{CD}^{+} \mathrm{T}$ cell population. $\mathrm{C} 57 \mathrm{BL} / 6$ mice were inoculated with a high dose of IOE via the i.d. or i.p. route and were sacrificed on day seven p.i. Splenocytes and liver mononuclear cells (LMNCs) were isolated, and percentages and absolute numbers of $\mathrm{CD}^{+}$and $\mathrm{CD}^{+} \mathrm{T}$ cells were determined by flow cytometric analysis. Total cell numbers were calculated by multiplying the percent positive within the gated lymphocyte population by the total viable splenocytes or LMNCs yield determined by trypan blue exclusion. A: I.p./lethal ehrlichial infection resulted in significant reductions in the percentages and absolute numbers of splenic $\mathrm{CD}^{+}{ }^{+} \mathrm{T}$ cells when compared with i.d./nonlethal infection. $\mathrm{CD}^{+} \mathrm{T}$ cell numbers in the LMNCs from i.d and i.p. inoculated mice were not significantly different $(P>0.05)$. B: I.p./lethal infection resulted in significantly lower percentages and absolute numbers of splenic $\mathrm{CD}^{+} \mathrm{T}$ cells and significantly higher percentages and absolute numbers of hepatic $\mathrm{CD}^{+} \mathrm{T}$ cells when compared with i.d./nonlethal infection. Data shown are representative of dot plots from three mice per group, and similar results were obtained in three independent experiments. ${ }^{*} P<0.05$, ** $P<0.01$.

\section{Lethal Ehrlichial Infection Enhanced Expression of Apoptotic and Cytotoxic Molecules in $\mathrm{CD}^{+}$ and $C D 8^{+} T$ Cells, Respectively, Compared with Nonlethal Infection}

We next examined the mechanisms that account for the decreased number of splenic $\mathrm{CD} 4^{+} \mathrm{T}$ cells observed in this study, as well as the apoptosis of $\mathrm{CD} 4^{+} \mathrm{T}$ cells and other hepatic cells during lethal infection as observed in our previous studies. ${ }^{5,9}$ Our data show that $C D 8^{+} T$ cells isolated from i.p./lethally infected mice are more cytotoxic and have greater expression of the intracellular cytotoxic molecule granzyme $B$, than those isolated from i.d./nonlethally infected mice $(7.74 \%$ vs. $0.79 \%$, Figure $2 A)$. Surprisingly, splenic $\mathrm{CD} 4^{+} \mathrm{T}$ cells isolated from i.p./lethally infected mice also expressed significantly higher levels of intracellular granzyme B when compared with those from non-lethally infected mice ( $2.82 \%$ vs. $0.35 \%$, Figure 2B). In addition, i.p./lethally infected mice had significantly greater expression of the apoptotic death receptor Fas on splenic $\mathrm{CD} 4^{+} \mathrm{T}$ cells compared with i.d./nonlethally infected mice (10.69\% vs. 0.43\%, Figure 2 C).

\section{Lethal Ehrlichial Infection Is Associated with Temporal and Spatial Changes in NKT Cells when Compared with Nonlethal Ehrlichial Infection}

We next examined the contributions of NKT cells to mild and severe ehrlichiosis by assessing NKT cell expansion and migration to sites of infection. On day 5 p.i., the percentage (data not shown) and absolute numbers (Figure $3 \mathrm{~A}$ ) of $\mathrm{CD}^{+}{ }^{+} \mathrm{NK} 1.1^{+} \mathrm{NKT}$ cells (measured by surface staining of CD3 and NK1.1 markers and mononuclear cell yield determined by trypan blue exclusion) in the spleen of i.p./lethally infected mice had begun to decline while those in the spleen and liver of i.d./nonlethally infected mice had begun to expand. On day 7 p.i., the total numbers (Figure 3B) and percentage (Figure 3, C and D) of $\mathrm{CD}^{+} \mathrm{NK} 1.1^{+}$NKT cells in the i.p./lethally infected mice were significantly lower in both spleen and liver when compared with nonlethal infection. Interestingly, early doxycycline treatment on day 1,2 , and 3 p.i. abrogated the infection and protected $78 \%$ ( 7 out of 9 ) of mice from fatal disease (see Supplemental Figure S1A at 
I.D. IOE (non-lethal) I.P. IOE (lethal)

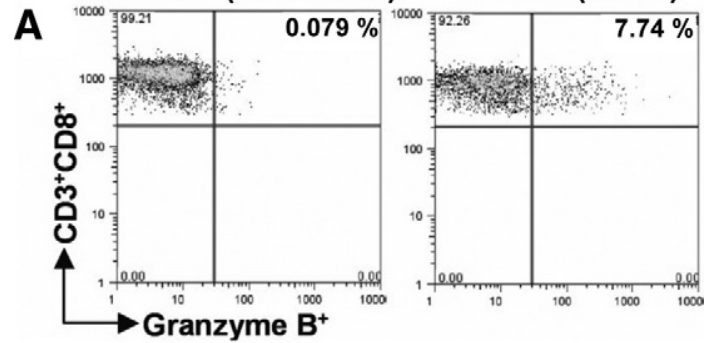

B
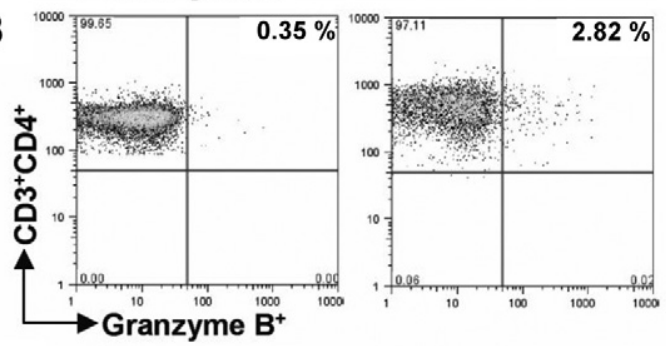

C

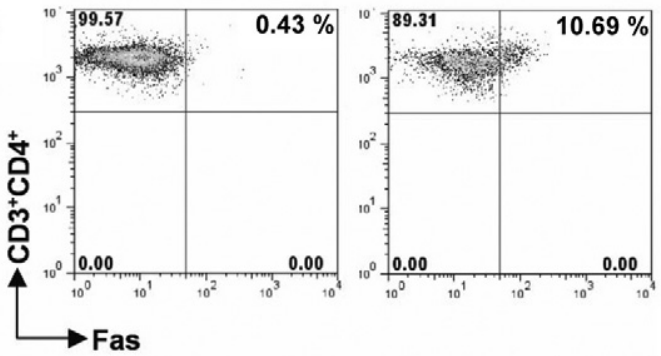

Figure 2. Lethal ehrlichial infection increased the expression of intracellular granzyme $\mathrm{B}$ in both $\mathrm{CD}^{+}$and $\mathrm{CD} 4^{+} \mathrm{T}$ cells and Fas expression on $\mathrm{CD} 4^{+} \mathrm{T}$ cells compared with nonlethal infection. Splenocytes isolated from lethally infected mice had significantly greater percentages of $\mathrm{CD}^{+} \mathrm{T}$ cells $(\mathbf{A})$ and $\mathrm{CD} 4^{+} \mathrm{T}$ cells $(\mathbf{B})$ expressing intracellular granzyme $\mathrm{B}$ than nonlethally infected mice. C: Splenocytes isolated from i.p./lethally infected mice also had significantly greater expression of Fas on CD $4^{+} \mathrm{T}$ cells compared with i.d. infected mice. Dot plots shown are representative of three mice per group, and similar results were obtained in two independent experiments.

http://ajp.amjpathol.org). In contrast, late treatment with doxycycline on days 5, 6, 7 p.i. did not protect mice from fatal disease (see Supplemental Figure S1A at http:// ajp.amjpathol.org), even though it restored the number of NKT cells in the spleen (see Supplemental Figure S1B at http:ajp.amjpathol.org) and decreased serum levels of cytokines associated with fatal disease such as IFN- $\gamma$, TNF- $\alpha$, and IL-10 (see Supplemental Figure S1C at $h t t p: / /$ ajp.amjpathol.org). These data suggest that the decreased number of NKT cells observed later in lethal infection could be triggered by the high bacterial burden and further indicate that fatal ehrlichiosis is an immunemediated disease.

\section{Lethal Ehrlichial Infection Induced Infiltration of CD11 $b^{+}$and $C D 11 c^{+}$Cells into the Liver Parenchyma}

We next examined the possibility that increased hepatic infiltration with antigen presenting cells may contribute to inflammatory liver injury and fatal disease. Within the CD3 ${ }^{-} \mathrm{NK} 1.1^{-}$population of LMNCs, we de-

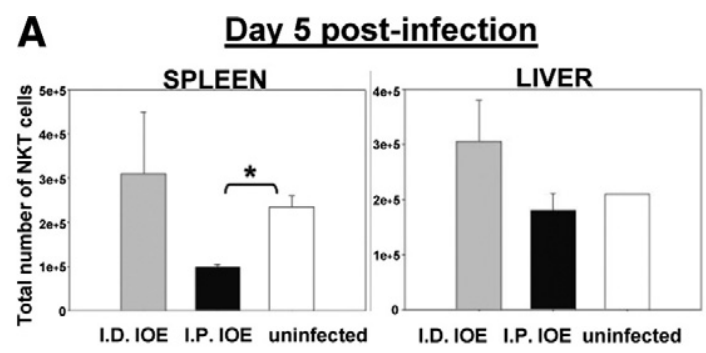

\section{B Day 7 post-infection}
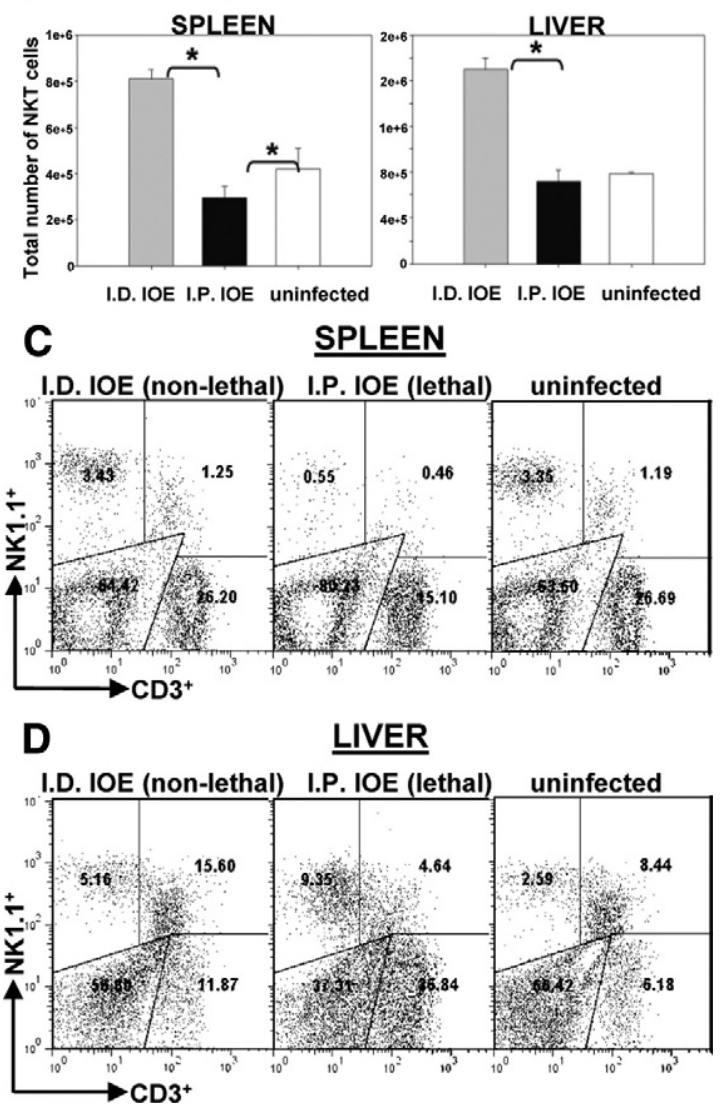

Figure 3. Lethal ehrlichiosis results in temporal and spatial differences in NKT cells, when compared with nonlethal disease. Splenocytes and LMNCs were isolated on day five and seven p.i. and were stained with fluorochromelabeled anti-CD3 and anti-NK1.1 mAbs to analyze the frequency of NKT $\left(\mathrm{CD} 3^{+} \mathrm{NK} 1.1^{+}\right)$cells by flow cytometry. The absolute number of splenic NKT cells was lower in i.p./lethally infected mice when compared with uninfected mice on day five p.i. (A). On day seven p.i., the absolute numbers (B) and percentages ( $\mathbf{C}$ and $\mathbf{D}$ ) of NKT cells in the spleens and livers of i.p./lethally infected mice were lower than that detected in i.d./nonlethally infected mice. The results in (A-D) are representative of three mice per group, and similar results were obtained in three independent experiments. ${ }^{*} P<0.05$.

tected significantly greater numbers of CD11b ${ }^{+}$(Figure $4 \mathrm{~A}$ ) cells and $\mathrm{CD}_{11 \mathrm{C}^{+}}$cells (data not shown) in lethally infected mice when compared with nonlethally or uninfected mice (31.02\% compared with $6.19 \%$ and $3.67 \%$, respectively). Within this $\mathrm{CD}^{-} \mathrm{NK} 1.1^{-} \mathrm{CD} 11 \mathrm{c}^{+}$population, the $\mathrm{CD}_{11 \mathrm{C}^{+}} \mathrm{LMNC}$ in lethally infected mice lacked the lineage markers for B cells (CD19) (data not shown), but had a higher percentage of $\mathrm{CD}_{11 \mathrm{C}^{+}}$cells expressing CD8 $\alpha$ $(7.32 \%)$ when compared with nonlethally $(1.76 \%)$ infected and uninfected mice $(0.47 \%)$ (Figure $4 \mathrm{~B})$. These results indicate an expansion of hepatic $\mathrm{CD} 8 \alpha^{+} \mathrm{CD} 11 \mathrm{C}^{+} \mathrm{DC}$ in lethal ehrlichial infection. 
A

B

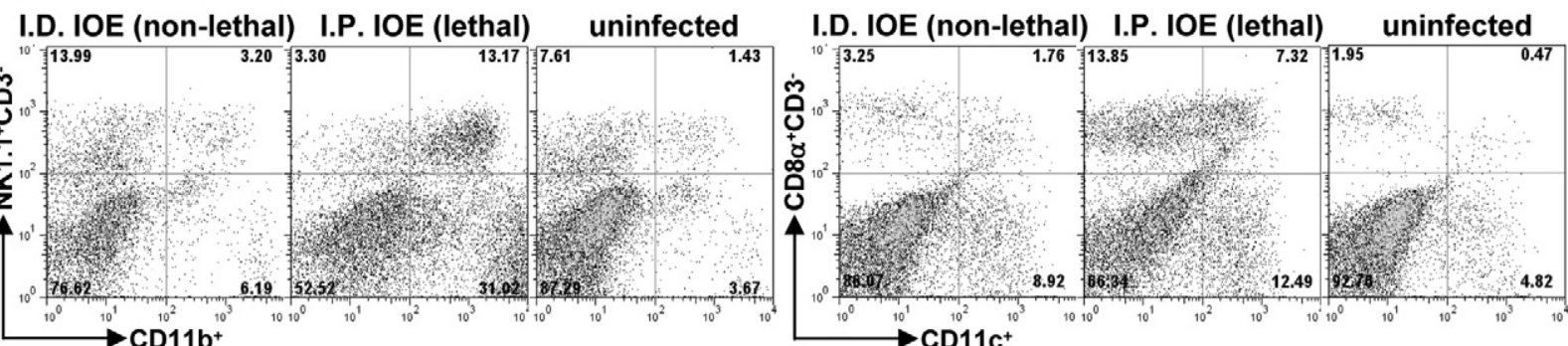

Figure 4. Hepatic CD8 $\alpha^{+} \mathrm{DC}$ and $\mathrm{CD} 11 \mathrm{~b}^{+}$monocytes expand following lethal ehrlichial infection. LMNCs were isolated as described in the Materials and Methods section on day five p.i. Within the liver monocyte/DC population analyzed by flow cytometry and selected based on forward and side scatter, lethally infected mice has higher percentages of $\mathrm{CD} 3^{-} \mathrm{NK} 1.1^{-} \mathrm{CD} 11 \mathrm{~b}^{+}$cells $(\mathbf{A})$ and $\mathrm{CD} 3^{-} \mathrm{CD} 8 \alpha^{+} \mathrm{CD} 11 \mathrm{c}^{+}$lymphoid dendritic cells $(\mathbf{B})$ when compared with uninfected and nonlethally infected mice. In addition, the CD11b ${ }^{+}$marker was expressed on a large percent CD3-NK1.1+ cells which are consistent with activated NK cells (A). Dot plots shown are representative of three mice per group, and similar results were obtained in two independent experiments.

\section{Lethal Ehrlichial Infection Stimulated Expansion and Migration of NK Cells to the Liver}

We next examined the effect of lethal and nonlethal ehrlichial infection on NK cell activation, expansion, and function. Lethal infection was associated with a significant decrease in the percentages and absolute numbers of NK cells in the spleen compared with nonlethal infection on days 5 (Figure 5, A and E) and 7 (Figures 5, C and G) p.i. In contrast, the percentage and total number of NK cells increased significantly in the liver of lethally infected mice on days 5 (Figure 5, B and F) and 7 (Figures 3D, and $5, \mathrm{D}$ and $\mathrm{H}$ ) p.i. compared with nonlethally infected mice. Hepatic $\mathrm{CD}^{-} \mathrm{NK} 1.1^{+} \mathrm{NK}$ cells from lethally infected mice also expressed CD11b, which is an activation marker of NK cells (Figure 4A). These data indicate that lethal ehrlichial infection induces spatial and temporal changes in activation and expansion or migration of NK cells to the liver, the main site of tissue injury.

\section{NK and NKT Cells are a Major Source of Intracellular Granzyme B, IFN- $\gamma$, and TNF- $\alpha$ in Lethal Ehrlichiosis}

Our previous studies demonstrated a significant association between overproduction of TNF- $\alpha$, apoptosis of $\mathrm{CD} 4^{+} \mathrm{T}$ cells, and tissue injury following lethal ehrlichial infection. ${ }^{4,5,12}$ To this end, we examined the cellular source of pro-inflammatory cytokines and cytotoxic molecules in infected mice. We detected significantly higher percentages of splenic NKT cells and NK cells, but not $\mathrm{CD}^{+}$and $\mathrm{CD}^{+} \mathrm{T}$ cells, producing TNF- $\alpha$, IFN- $\gamma$, and granzyme B in lethally infected mice when compared with nonlethally or uninfected mice on day 7 p.i (Figure 6, A-C). However, since the number of NKT cells decreased substantially in lethally infected mice on day 7 p.i. (Figure 3B), these data indicate that NK cells are the major cellular source of TNF- $\alpha$, IFN- $\gamma$, and granzyme B in lethally infected mice.
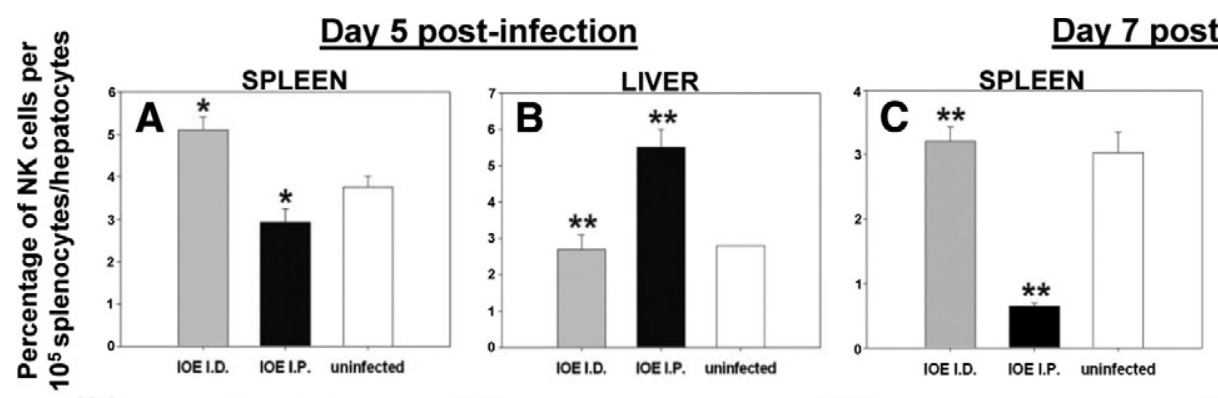

\section{Day 7 post-infection}
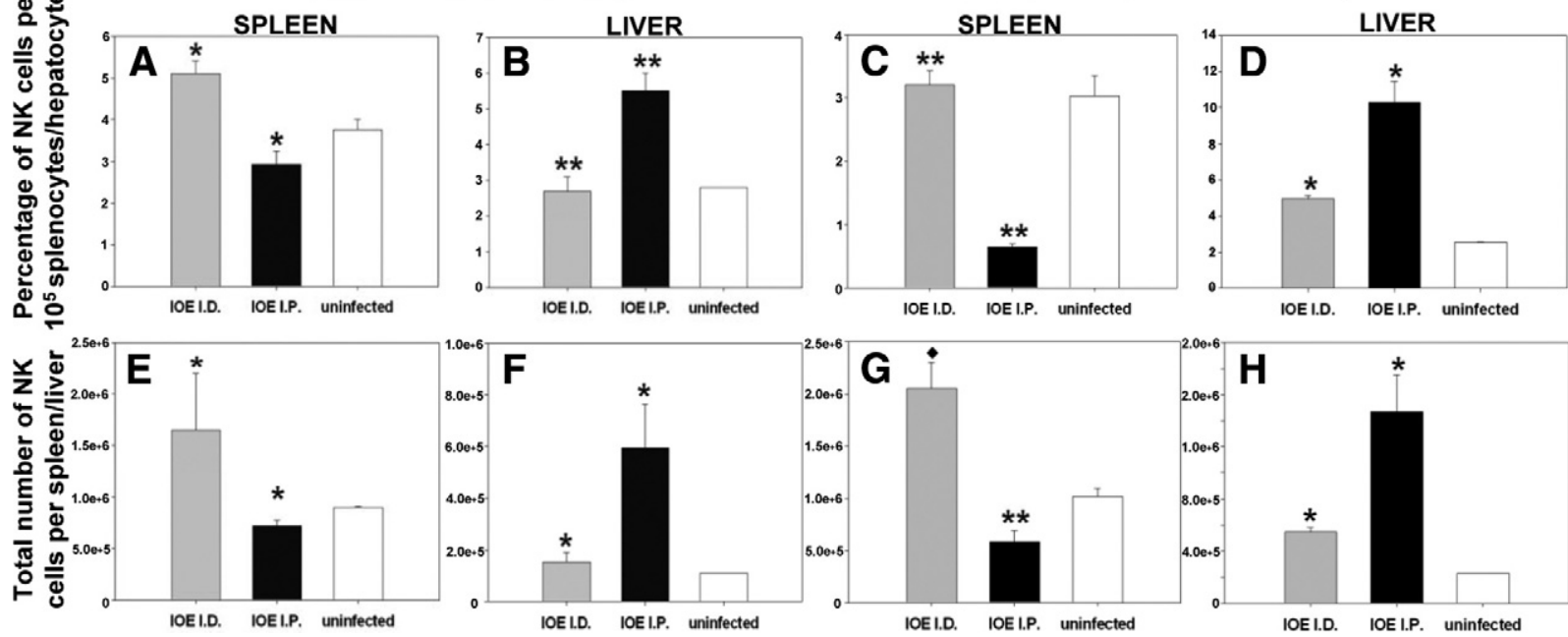

Figure 5. Lethal ehrlichiosis results in temporal and spatial differences in NK cells, when compared with nonlethal disease. Splenic and hepatic mononuclear cells were stained with fluorescent labeled murine anti-CD3 and anti-NK1.1 mAbs followed by flow cytometric analysis. The percentage and absolute number of NK cells were significantly lower in the spleen of i.p./lethally infected mice on days five (A and $\mathbf{E}$ ) and seven $(\mathbf{C}$ and $\mathbf{G})$ p.i. than that in i.d/nonlethally infected mice. The percentage and absolute numbers of NK cells were significantly greater in the liver of i.p./lethally infected mice on days five (B and $\mathbf{F})$ and seven ( $\mathbf{D}$ and $\mathbf{H})$ p.i., as compared with i.d./nonlethally infected mice. ${ }^{*} P<0.05,{ }^{* * *} P<0.01$. 

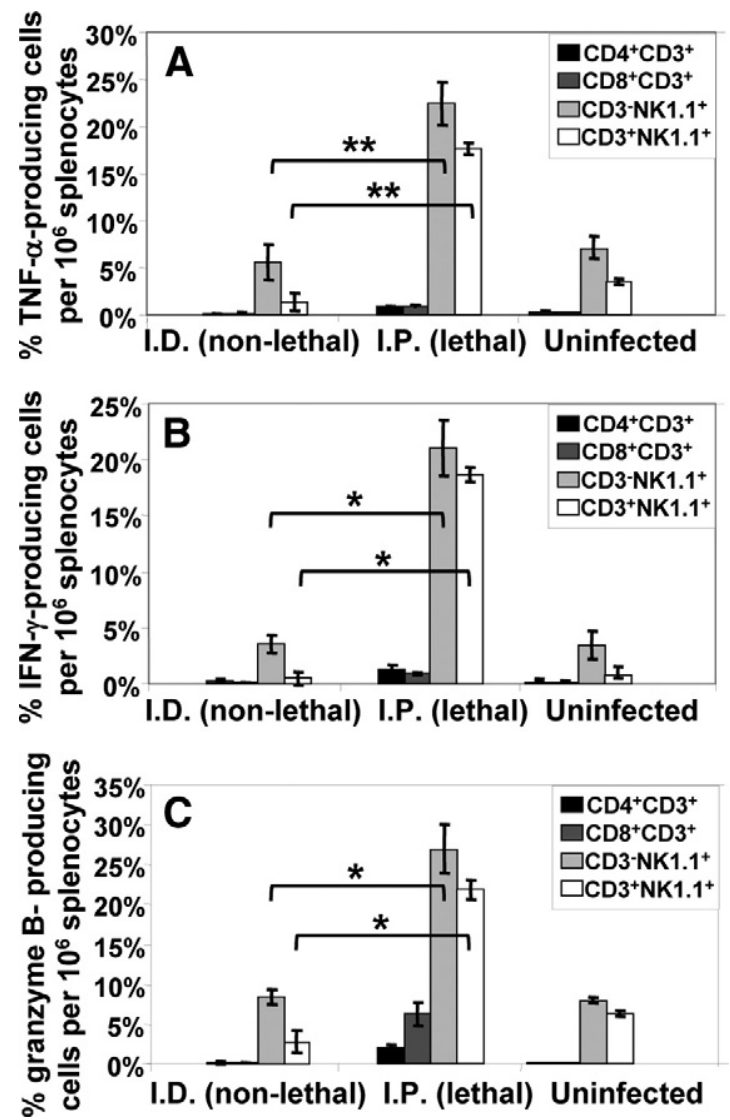

Figure 6. NK and NKT cell populations produced high concentrations of intracellular TNF- $\alpha$, IFN- $\gamma$, and granzyme B during severe ehrlichiosis. NK and NKT cells in the spleen and liver were characterized by dual staining with NK1.1 and CD3 or DX5 and CD3. NK cells are NK1.1 $1^{+}$or DX5 $5^{+}$and $\mathrm{CD}^{-}$while NKT cells are NK1. $1^{+}$or DX $5^{+}$and $\mathrm{CD}^{+}$. Data shown are from staining with anti-NK1.1 and anti-CD3, which are similar to the results obtained when anti-DX5 and anti-CD3 Abs were used. Significantly greater percentages of TNF- $\alpha(\mathbf{A}), \operatorname{IFN}-\gamma(\mathbf{B})$, and granzyme B (C) producing or expressing NK and NKT cells, but not $\mathrm{CD}^{+}$and $\mathrm{CD}^{+}{ }^{+} \mathrm{T}$ cells, were observed in the spleens of i.p./lethally infected mice than in i.d./nonlethally infected or uninfected mice on day seven p.i. Data shown are mean \pm SD of three mice per group with similar results in three independent experiments. ${ }^{*} P<0.05$, ${ }^{* * *} P<0.01$.

\section{Lethal Infection Was Associated with Higher Serum Levels of IL-12p40, IL-18, MCP-1, and RANTES, When Compared with Nonlethal Infection}

We measured the serum levels of several cytokines and chemokines in i.d./nonlethally and i.p./lethally infected mice that could contribute to substantial hepatic expansion and/or migration of NK cells, CD8 ${ }^{+} \mathrm{T}$ cells, $\mathrm{DC}$, and monocytes to the liver. Compared with nonlethal infection, lethal ehrlichial infection was associated with significantly higher serum levels of IL-18, MCP-1 and RANTES (Figure 7A) on day 7 p.i Interestingly, although the serum levels of IL-12p70 were not significantly different between mild and severe disease (data not shown), lethal disease was associated with a higher level of serum IL-12p40 than nonlethal disease (Figure 7A).

IL-18, together with IL-12p40, is a potent activator and inducer of cytotoxic NK cells and NKT cells in the liver and has been implicated in the pathogenesis of septic
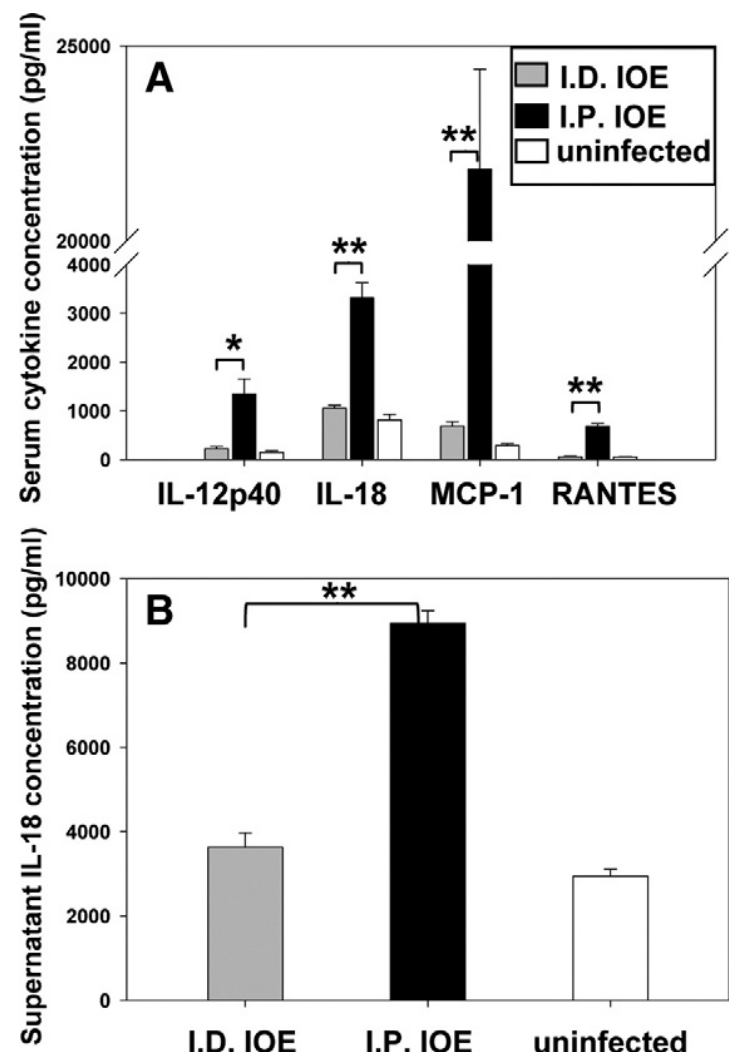

Figure 7. Lethal disease increased systemic concentrations of IL-12p40, IL-18, MCP-1, and RANTES, and increased IL-18 production by liver mononuclear cells. A: The serum levels of IL-12p40, IL-18, MCP-1, and RANTES were measured on day seven p.i. and were significantly higher in the i.p./lethally infected mice. B: LMNCs were pooled from three mice per group, the cells were stimulated in vitro with IOE antigens, and IL-18 was measured in cell culture supernatants. LMNCs isolated from i.p./lethally infected mice produced significantly greater amounts of IL-18 than those from i.d./nonlethally infected mice. Data are representative of three mice per group, and similar results were obtained in three independent experiments. ${ }^{*} P<0.05$, ${ }^{* * *} P<0.01$

shock caused by other bacterial and viral infections. ${ }^{25,33,34}$ We examined here whether this cytokine is produced during severe ehrlichiosis. Strikingly, LMNCs (Figure 7B) and splenocytes (data not shown) from lethally infected mice produced significantly higher levels of IL-18 on in vitro antigen (IOE)-specific stimulation compared with LMNCs and splenocytes from nonlethally infected mice.

\section{NK Cell Cytotoxic Function and Cytokine Production Are Enhanced in Lethal Ehrlichial Infection}

Next, we investigated whether lethal ehrlichial infection induced greater cytotoxic function of NK cells. To explore this possibility, the killing of YAC-1 cells by NK cells and the production of different cytokines were examined. Compared with splenocytes from uninfected or nonlethally infected mice, NK cells from the spleen of lethally infected mice readily killed YAC-1 target cells (Figure 8, $A-C)$, and this cytotoxicity was significantly decreased when NK cells were depleted in i.p./lethally infected mice in vivo using anti-asialo GM1-Ab (Figure 8D). Depletion of 


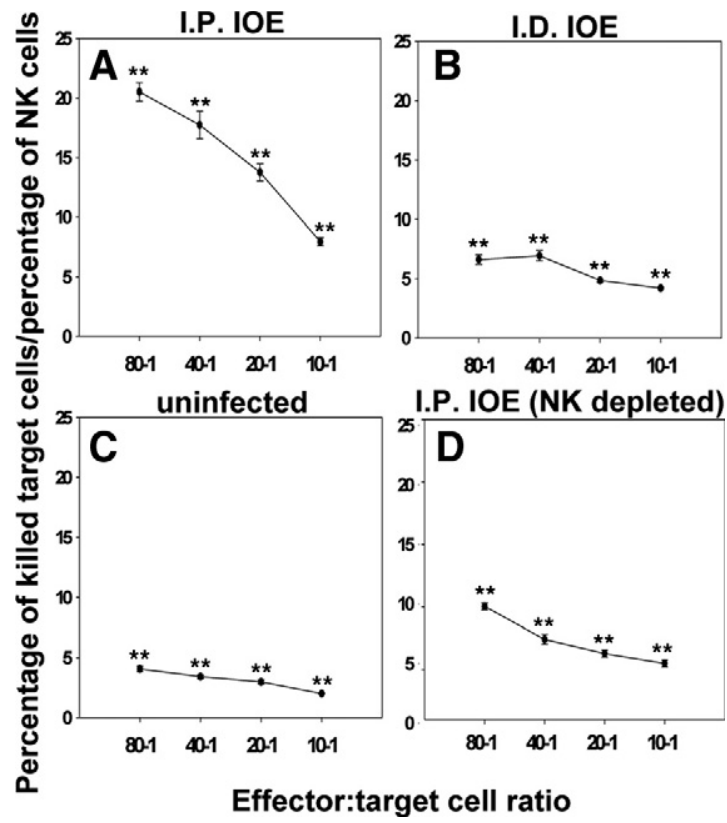

Figure 8. Lethal ehrlichial infection resulted in increased cytotoxicity of splenic NK cells when compared with nonlethal infection. Splenocytes were isolated and cytotoxicity was examined on day seven p.i. as described in Materials and Methods. The percentage of YAC-1 target cells killed was normalized relative to the number of splenic NK cells in the different groups of mice (A-D). Splenocytes from i.p./lethally infected mice (A) showed significantly higher cytotoxic activity, in a dose-dependent manner, against YAC-1 cells than those from i.d./nonlethally infected mice (B) uninfected mice treated with control $\mathrm{Ab}(\mathbf{C})$, or i.p./lethally infected, NK cell-depleted (anti-asialo-GM1 treated) mice (D). Data are expressed as the mean \pm SD of three mice per group, and similar results were obtained in two independent experiments. ${ }^{* *} P<0.01$

NK cells in lethally infected mice significantly decreased the serum levels of IFN- $\gamma$, TNF- $\alpha$, and IL-10 compared with lethally infected, control antibody-treated mice (Figure 9A). Collectively, these data suggest that NK cell cytotoxic functions are enhanced in i.p/lethally infected mice and that NK cells are major producers of pro-and anti-inflammatory cytokines observed during Ehrlichia-induced toxic shock-like syndrome. ${ }^{4,5}$

\section{Enhanced Protective Immunity Against Ehrlichia and Attenuation of Tissue Injury in NK Cell-Depleted Mice}

We measured the effect of NK cell depletion on the bacterial burden in lethally infected mice. Surprisingly,
NK cell depletion resulted in a dramatic decrease in bacterial burden in the liver, lung and spleen of lethally infected mice on day 7 p.i., when compared with similarly infected, control antibody-treated mice (Figure 9B). On day 9 p.i., a decreased bacterial burden was also evident in the liver, but not in the lung or spleen, which corresponds to a repopulation of NK cells in these organs (data not shown). These data suggest that NK cells suppress protective anti-ehrlichial immunity.

Next, we investigated the role of NK cells in the development of hepatic immunopathology following lethal ehrlichial infection. NK cell depletion abrogated liver injury, inflammation, and apoptosis as detected by histopathology (Figure 10, $A$ and $B$ ) and TUNEL assays (Figure 10, C-F) when compared with lethally infected sham control mice on day 7 p.i. However, on day 9 p.i., both NK cell-depleted and control antibody-treated mice developed secondary necrosis, followed by death on day 11 p.i. Interestingly, mortality of the NK cell-depleted mice was accompanied by repopulation of $\mathrm{CD}^{-} \mathrm{NK} 1.1^{+} \mathrm{NK}$ cells in the spleen and liver as measured by flow cytometry (data not shown). These data demonstrate that the late cytokine storm and the extent of liver injury in response to lethal IOE infection are dependent on NK cells.

\section{Discussion}

The present study demonstrates that NK cell depletion in lethally infected mice improved protective immunity against virulent Ehrlichia and prevented the development of liver injury, providing evidence for a major pathogenic role of NK cells in fatal ehrlichiosis. Our murine models of mild and fatal ehrlichiosis clearly indicate that pathogenic host immune responses mediate tissue injury and fatal disease. Our studies show a differential localization or expansion of NK cells in the spleen and the liver of nonlethally and lethally infected mice. Higher numbers of NK cells in the liver, but not in the spleen, of lethally infected mice could be due to proliferation of hepatic NK cells or their trafficking to the Ehrlichia-infected microenvironment. Elevated production of IL-18, one of the main cytokines that promotes activation and expansion of NK cells, ${ }^{35}$ by LMNCs suggests that the hepatic microenvironment enhances NK expansion and proliferation. In addition, increased production of several chemokines including RANTES and MCP-1 that are potent NK cell and
A

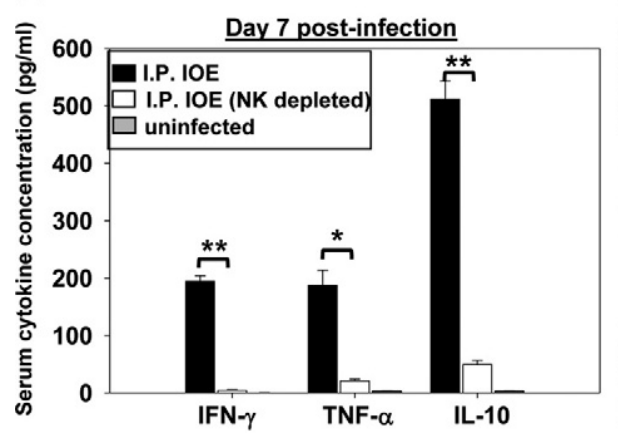

B

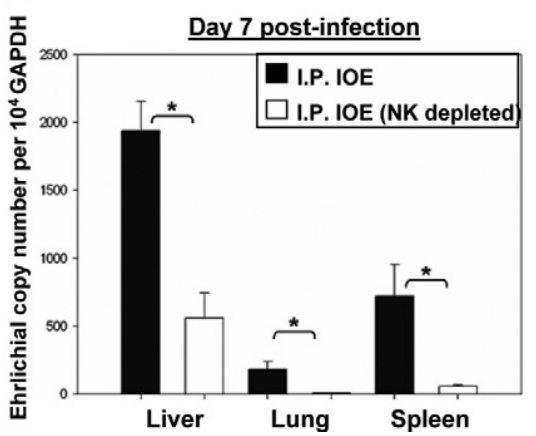

Figure 9. NK cell depletion resulted in significantly lower serum IFN- $\gamma$, TNF- $\alpha$, and IL-10 concentrations, and decreased the bacterial burden. A: NK cell depletion resulted in significantly decreased serum levels of the IFN- $\gamma$, TNF- $\alpha$, and IL-10 in IOE-infected, NK cell-depleted mice when compared with sham-depleted infected mice on day seven p.i. as measured by cytokine enzyme-linked immunosorbent assay. B: Mice depleted of NK cells had significantly lower ehrlichial burdens in the liver, lung, and spleen than sham-depleted infected mice on day seven p.i. as determined by real time PCR Data shown are mean \pm SD of three mice per group with similar results in three independent experiments. ${ }^{*} P<0.05,{ }^{* *} P<0.01$. 


\section{I.P. IOE INFECTED (NK depleted)}

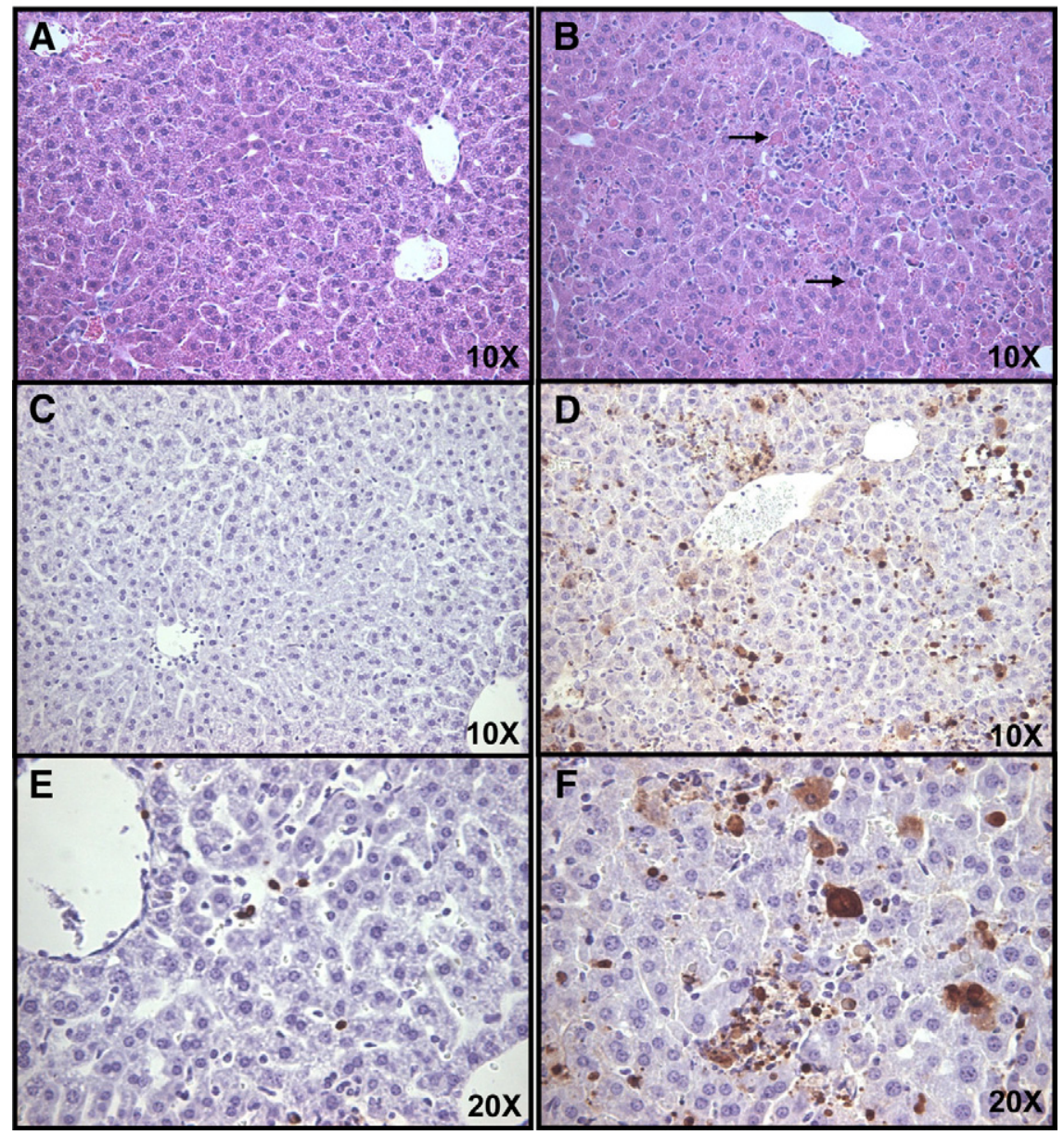

Figure 10. NK cells played a role in severe liver injury/apoptosis in lethal disease. On day seven p.i., livers were harvested from i.p./lethally infected, NK cell-depleted mice (A, C, and E), infected, sham-depleted mice $(\mathbf{B}, \mathbf{D}$, and $\mathbf{F})$, or uninfected mice injected with PBS only (data not shown). H\&E staining showed minimal hepatic pathology in the infected NK cell-depleted mice (A) compared with infected sham-depleted mice, which had multiple foci of host cell death (arrows). B: TUNEL assays showed substantially lower numbers of apoptotic cells in the infected NK cell-depleted mice (C and $\mathbf{E}$ ) with fewer than one to two apoptotic cells observed per $\times 20$ field compared with to 30 to 50 apoptotic cells per $\times 20$ field in the infected shamdepleted control mice (D and F). Uninfected control mice had only one apoptotic cell per ten fields. Data are representative of several liver sections from three mice per group. Similar results were obtained in two independent experiments
T cell chemoattractants ${ }^{36,37}$ suggest that enhanced trafficking of NK cells to the liver may contribute to severe tissue injury and host cell death in lethal disease. This conclusion is consistent with previous studies showing higher levels of RANTES in patients with fatal Mediterranean spotted fever rickettsiosis compared with patients with mild disease, ${ }^{38}$ as well as higher serum levels of CCL2 (MCP-1) in fatal murine primary and secondary ehrlichiosis compared with mild ehrlichiosis where blocking CCL2 ameliorates fatal disease. ${ }^{39}$ In an influenza model where severe disease is due to $T$ cell-mediated injury, it has been suggested that TNF- $\alpha$ regulates the production of MCP-1 and possibly other chemokines by host cells. ${ }^{40,41}$ Thus, it is possible that during fatal primary ehrlichiosis the production of TNF- $\alpha$ by NK cells (Figure 6A), as well as by CD8 ${ }^{+} \mathrm{T}$ cells as we have shown before, ${ }^{5,12}$ promotes increased chemokine production and chemokine-dependent inflammation resulting in liver pathology. Migration of NK cells from the spleen and bone marrow into the liver has also been described in concanavalin A-induced hepatitis. ${ }^{24} \mathrm{NK}$ cells have also been shown to migrate from the blood and spleen into the inflamed peritoneal cavity during polymicrobial sepsis induced by cecal ligation and puncture. ${ }^{42}$ In addition to the chemotactic effects of those chemokines, it is also possible that elevated levels of MCP-1 and RANTES, as observed in the current study, may contribute to the observed lymphopenia in fatal murine ehrlichiosis, mainly by reducing $\mathrm{CD}^{+} \mathrm{T}$ cell proliferation as suggested by other studies. For example, increased production of MCP-1 and RANTES during infection with Anaplasma marginale, the causative agent of human granulocytic ehrlichiosis (currently known as human anaplasmosis), was suggested as a potential mechanism that might play a role in bone marrow suppression and resulting cytopenias in human anaplasmosis. ${ }^{43,44}$ Other studies indicated that high concentrations of RANTES could enhance T cell apoptosis. ${ }^{45}$ Our further studies will examine the roles of these chemokines in the pathogenesis of fatal HME.

Our data clearly show that NK cells play a key role in tissue injury in severe and fatal disease. The mechanisms by which NK cells potentiate tissue injury after lethal ehrlichial infection are not completely understood. However, it is possible that NK cells mediate fatal ehrlichiosis by enhancing local and systemic inflammation and direct cytotoxic killing of host cells, as evidenced by the abrogation of systemic pro-inflammatory cytokine production (Figure 6, A-C and 9A) and minimal tissue damage (Figure 10) following NK cell depletion. In addition, NK cells may enhance the generation of pathogenic cytotoxic $\mathrm{CD} 8^{+} \mathrm{T}$ cells, which in turn promote tissue damage and apoptosis of protective $\mathrm{CD} 4^{+} \mathrm{T}$ cells as we have shown 
previously. ${ }^{12}$ In support of this conclusion, we observed increased cytotoxicity in splenic CD $8^{+} \mathrm{T}$ cells and greater infiltration of $\mathrm{CD} 8^{+} \mathrm{T}$ cells in the liver of lethally infected mice (Figures 1 and 2).

Depletion of NK cells in i.p./lethally infected mice resulted in more effective clearance of Ehrlichia. These results are similar to our previous study showing decreased ehrlichial burden in $\beta_{2} \mathrm{~m}^{-1-}$ mice ${ }^{12}$; however, differs from that observed in lethally infected CD1d ${ }^{-/-}$ mice, where absence of NKT cells results in an increased bacterial burden. ${ }^{13} \mathrm{CD} 4{ }^{+}$Th1 and NKT cells mediate protection against Ehrlichia through IFN- $\gamma$ production. Our current and previous data ${ }^{4,12}$ show that fatal disease is associated with suppressed $\mathrm{CD} 4^{+} \mathrm{T}$ cell proliferation and apoptosis of $\mathrm{CD} 4^{+} \mathrm{T}$ cells. These observations were also associated with a significant increase in the number of intrahepatic NK cells (Figure 3D, 4A, and 5H). Therefore, it is possible that NK cells inhibit protective immunity against Ehrlichia in lethal ehrlichiosis through either a direct or an indirect mechanism that causes apoptosis and/or suppression of IFN- $\gamma$ producing $\mathrm{CD}^{+}{ }^{+}$Th1 cells and NKT cells. Decreased IL-10 levels in NK cell depleted mice (Figure 9A) suggest that NK cell-mediated production of $\mathrm{IL}-10$ may play a role in the generation of the $\mathrm{CD} 4^{+} \mathrm{Th} 1$ hyporesponsiveness in fatal ehrlichiosis.

Unexpectedly, NK cell-deficient mice succumbed to lethal disease similar to infected sham-depleted controls. Mortality of NK cell-depleted mice and sham-depleted controls was associated with the development of hepatocellular necrosis on day 9 p.i. and repopulation of NK cells in the spleen (data not shown). Repopulation of NK cells could be due to incomplete depletion of NK cells and/or restoration of their numbers, as NK cells are known to arise locally from hepatic hematopoietic stem cells in response to constitutive and inducible expression of IL-15 during other infections. ${ }^{46}$ Our data show that the peak increase in numbers of NK cells during severe ehrlichiosis occurs on day 7 p.i., when the experimentally administered anti-asialo GM1 antibody concentration in vivo might not have been sufficient to maintain depletion of the large numbers of expanded NK cells.

Cross talk between NK cells and antigen presenting cells, mainly DC, is critical for NK cell activation as well as DC maturation and induction of the acquired immune response against infections with several intracellular pathogens. ${ }^{47-52}$ Our results demonstrated substantial infiltration or expansion of $\mathrm{CD} 8 \alpha^{+} \mathrm{DC}$ in the liver, but not in the spleen, of lethally infected mice when compared with i.d./nonlethal infection. $\mathrm{CD} 8 \alpha^{+}$DCs produce large amounts of IL-12 and IL-18 and are responsible for activation and mobilization of NK cells $\mathrm{s}^{22,24}$ and cross-priming of $C D 8^{+} T$ cells in vivo. ${ }^{19}$ Our data demonstrated that lethal Ehrlichia infection induced increased production of IL-18 by LMNCs as well as elevated serum levels of IL-12p40 and IL-18 (Figure 7A). Although, the cellular sources of these cytokines are not yet known, it is possible that hepatic CD $8 \alpha^{+}$DC produce IL-18 and IL-12p40 during lethal ehrlichial infection, which in turn enhances activation and cytotoxic functions of NK cells and $C D 8^{+} T$ cells leading to tissue injury. This conclusion is supported by studies showing that IL-18 plays a pathogenic role in several infectious diseases including LPS-induced multiorgan failure and sepsis where high levels of IL-18 correlate with the severity of hepatic damage, while absence of IL-18 enhances resistance to LPS-induced sepsis. ${ }^{15}$ In conclusion, these findings provide new information regarding the contribution of NK cells to the pathogenesis of fatal ehrlichiosis and the potential mechanisms by which NK cells facilitate the local inflammatory response leading to severe organ pathology during Ehrlichia-induced toxic shock-like syndrome.

\section{Acknowledgments}

We thank Doris Baker and Sherrill Hebert for their excellent secretarial assistance. We also thank Linda Muehlberger for her expert histological preparations and Purnima Ghose, Emily Crossley and Jeffrey Jordan for their assistance with flow cytometry experiments.

\section{References}

1. Olano JP, Walker DH: Human ehrlichioses. Med Clin North Am 2002, 86:375-392

2. Walker DH, Dumler JS: Human monocytic and granulocytic ehrlichioses. Discovery and diagnosis of emerging tick-borne infections and the critical role of the pathologist. Arch Pathol Lab Med 1997, 121:785-791

3. Fichtenbaum CJ, Peterson LR, Weil GJ: Ehrlichiosis presenting as a life-threatening illness with features of the toxic shock syndrome. Am J Med 1993, 95:351-357

4. Ismail N, Soong L, McBride JW, Valbuena G, Olano JP, Feng H-M Walker $\mathrm{DH}$ : Overproduction of TNF- $\alpha$ by $\mathrm{CD}^{+}$type 1 cells and down-regulation of IFN- $\gamma$ production by $\mathrm{CD} 4^{+}$Th1 cells contribute to toxic shock-like syndrome in an animal model of fatal monocytotropic ehrlichiosis. J Immunol 2004, 172:1786-1800

5. Ismail N, Stevenson HL, Walker $\mathrm{DH}$ : Role of tumor necrosis factor alpha (TNF-alpha) and interleukin-10 in the pathogenesis of severe murine monocytotropic ehrlichiosis: increased resistance of TNF receptor p55- and p75-deficient mice to fatal ehrlichial infection. Infect Immun 2006, 74:1846-1856

6. Sehdev AE, Dumler JS: Hepatic pathology in human monocytic ehrlichiosis. Ehrlichia chaffeensis infection. Am J Clin Pathol 2003, 119:859-865

7. Walker DH: Emerging human ehrlichioses: recently recognized widely distributed, life-threatening tick-borne diseases. Emerging infections I. Edited by WM Scheld, D Armstrong, and JM Hughes. Washington, AMS Press, 1998, pp. 81-91

8. Shibata S, Kawahara M, Rikihisa Y, Fujita H, Watanabe $Y$, Suto C, Ito $\mathrm{T}$ : New Ehrlichia species closely related to Ehrlichia chaffeensis isolated from Ixodes ovatus ticks in Japan. J Clin Microbiol 2000, 38:1331-1338

9. Stevenson HL, Jordan JM, Peerwani Z, Wang HQ, Walker DH, Ismail $\mathrm{N}$ : An intradermal environment promotes a protective type-1 response against lethal systemic monocytotropic ehrlichial infection. Infect Immun 2006, 74:4856-4864

10. Bitsaktsis C, Huntington J, Winslow GM: Production of IFN- $\gamma$ by CD4 $\mathrm{T}$ cells is essential for resolving ehrlichia infection. J Immunol 2004, 172:6894-6901

11. Bitsaktsis C, Winslow G: Fatal recall responses mediated by CD8 T cells during intracellular bacterial challenge infection. J Immunol 2006, 177:4644-4651

12. Ismail N, Crossley EC, Stevenson HL, Walker DH: Relative importance of T cell subsets in monocytotropic ehrlichiosis: A novel effector mechanism involved in Ehrlichia-induced immunopathology in murine ehrlichiosis. Infect Immun 2007, 75:4608-4620

13. Stevenson HL, Crossley EC, Thirumalapura N, Walker DH, Ismail N: Regulatory roles of CD1d-restricted NKT cells in the induction of toxic 
shock-like syndrome in an animal model of fatal ehrlichiosis. Infect Immun 2008, 76:1434-1444

14. Mattner J, Debord KL, Ismail N, Goff RD, Cantu C, III, Zhou D, Saint-Mezard P, Wang V, Gao Y, Yin N, Hoebe K, Schneewind O, Walker D, Beutler B, Teyton L, Savage PB, Bendelac A: Exogenous and endogenous glycolipid antigens activate NKT cells during microbial infections. Nature 2005, 434:525-529

15. Tsutsui H, Adachi K, Seki E, Nakanishi K: Cytokine-induced inflammatory liver injuries. Curr Mol Med 2003, 3:545-559

16. Bancroft GJ: The role of natural killer cells in innate resistance to infection. Curr Opin Immunol 1993, 5:503-510

17. Berg RE, Crossley E, Murray S, Forman J: Relative contributions of NK and CD8 T cells to IFN-gamma mediated innate immune protection against Listeria monocytogenes. J Immunol 2005, 175:1751-1757

18. Barry M, Bleackley RC: Cytotoxic T lymphocytes: all roads lead to death. Nat Rev Immunol 2002, 2:401-409

19. Nakanishi K, Yoshimoto $\mathrm{T}$, Tsutsui $\mathrm{H}$, Okamura H: Interleukin-18 is a unique cytokine that stimulates both Th1 and Th2 responses depending on its cytokine milieu. Cytokine Growth Factor Rev 2001, 12:53-72

20. Okamura H, Tsutsi H, Komatsu T, Yutsudo M, Hakura A, Tanimoto T, Torigoe K, Okura T, Nukada Y, Hattori K, Akita K, Namba M, Tanabe F, Konishi K, Fukuda S, Kurimoto M: Cloning of a new cytokine that induces IFN-gamma production by T cells. Nature 1995, 378: $88-91$

21. Trapani JA, Smyth MJ: Functional significance of the perforin/granzyme cell death pathway. Nat Rev Immunol 2002, 2:735-747

22. Tripp CS, Wolf SF, Unanue ER: Interleukin 12 and tumor necrosis factor alpha are costimulators of interferon gamma production by natural killer cells in severe combined immunodeficiency mice with listeriosis, and interleukin 10 is a physiologic antagonist. Proc Nat Acad Sci USA 1993, 90:3725-3729

23. Tripp CS, Gately MK, Hakimi J, Ling P, Unanue ER: Neutralization of IL-12 decreases resistance to Listeria in SCID and C.B-17 mice. Reversal by IFN-gamma J Immunol 1994, 152:1883-1887

24. Wald O, Weiss ID, Wald H, Shoham H, Bar-Shavit Y, Beider K, Galun E, Weiss L, Flaishon L, Shachar I, Nagler A, Lu B, Gerard C, Gao JL, Mishani E, Farber J, Peled A: IFN-gamma acts on T cells to induce NK cell mobilization and accumulation in target organs. J Immunol 2006, 176:4716-4729

25. Dunn C, Brunetto M, Reynolds G, Christophides T, Kennedy PT, Lampertico P, Das A, Lopes AR, Borrow P, Williams K, Humphreys E, Afford S, Adams DH, Bertoletti A, Maini MK: Cytokines induced during chronic hepatitis B virus infection promote a pathway for NK cell-mediated liver damage. J Exp Med 2007, 204:667-680

26. Liu ZX, Govindarajan S, Okamoto S, Dennert G: NK cells cause liver injury and facilitate the induction of $T$ cell-mediated immunity to a viral liver infection. J Immunol 2000, 164:6480-6486

27. Inayoshi M, Naitou H, Kawamori F, Masuzawa T, Ohashi N: Characterization of Ehrlichia species from Ixodes ovatus ticks at the foot of Mt. Fuji, Japan. Microbiol Immunol 2004, 48:737-745

28. Sotomayor E, Popov V, Feng H-M, Walker DH, Olano JP: Animal model of fatal human monocytotropic ehrlichiosis. Am J Pathol 2001, 158:757-769

29. Morsy MA, Norman PJ, Mitry R, Rela M, Heaton ND, Vaughan RW: Isolation, purification and flow cytometric analysis of human intrahepatic lymphocytes using an improved technique. Lab Invest 2005, 85:285-296

30. Ortaldo JR, Sharrow SO, Timonen T, and Herberman RB: Determination of surface antigens on highly purified human NK cells by flow cytometry with monoclonal antibodies. J Immunol 1981, 127:2401-2409

31. Belperio JA, Keane MP, Burdick MD, Lynch JP, III, Xue YY, Li K, Ross DJ, Strieter RM: Critical role for CXCR3 chemokine biology in the pathogenesis of bronchiolitis obliterans syndrome. J Immunol 2002, 169:1037-1049

32. Parker GA, Picut CA: Liver immunobiology. Toxicol Pathol 2005, 33:52-62

33. El-Masry S, Lotfy M, Nasif WA, El-Kady IM, Al-Badrawy M: Elevated serum level of interleukin (IL)-18, interferon (IFN)-gamma and soluble Fas in patients with pulmonary complications in tuberculosis. Acta Microbiol Immunol Hung 2007, 54:65-77
34. Kawakami K, Kinjo Y, Uezu K, Miyagi K, Kinjo T, Yara S, Koguchi Y, Miyazato A, Shibuya K, Iwakura Y, Takeda K, Akira S, Saito A: Interferon-gamma production and host protective response against Mycobacterium tuberculosis in mice lacking both IL-12p40 and IL-18. Microbes Infect 2004, 6:339-349

35. French AR, Holroyd EB, Yang L, Kim S, Yokoyama WM: IL-18 acts synergistically with IL-15 in stimulating natural killer cell proliferation. Cytokine 2006, 35:229-234

36. Inngjerdingen M, Damaj B, Maghazachi AA: Expression and regulation of chemokine receptors in human natural killer cells. Blood 2001, 97:367-375

37. Loetscher P, Seitz M, Clark-Lewis I, Baggiolini M, Moser B: Activation of NK cells by CC chemokines. Chemotaxis, $\mathrm{Ca} 2+$ mobilization, and enzyme release. J Immunol 1996, 156:322-327

38. de Sousa R, Ismail N, Nobrega SD, Franca A, Amaro M, Anes M, Pocas J, Coelho R, Torgal J, Bacellar F, Walker DH: Intralesional expression of mRNA of interferon- gamma, tumor necrosis factoralpha, interleukin-10, nitric oxide synthase, indoleamine-2,3-dioxygenase, and RANTES is a major immune effector in Mediterranean spotted fever rickettsiosis. J Infect Dis 2007, 196:770-781

39. Bitsaktsis C, Nandi B, Racine R, Macnamara KC, Winslow G: T cell-independent humoral immunity is sufficient for protection against fatal intracellular Ehrlichia infection. Infect Immun 2007, 75:4933-4941

40. Crowe CR, Chen K, Pociask DA, Alcorn JF, Krivich C, Enelow RI, Ross TM, Witztum JL, Kolls JK: Critical role of IL-17RA in immunopathology of influenza infection. J Immunol 2009, 183:5301-5310

41. Xu L, Yoon H, Zhao MQ, Liu J, Ramana CV, Enelow RI: Cutting edge: pulmonary immunopathology mediated by antigen-specific expression of TNF-alpha by antiviral CD8+ T cells. J Immunol 2004, 173:721-725

42. Etogo AO, Nunez J, Lin CY, Toliver-Kinsky TE, Sherwood ER: NK but not CD1-restricted NKT cells facilitate systemic inflammation during polymicrobial intra-abdominal sepsis. J Immunol 2008, 180:6334-6345

43. Klein MB, Hu S, Chao CC, Goodman JL: The agent of human granulocytic ehrlichiosis induces the production of myelosuppressing chemokines without induction of proinflammatory cytokines. J Infect Dis 2000, 182:200-205

44. Miura K, Rikihisa Y: Liver transcriptome profiles associated with strain-specific Ehrlichia chaffeensis-induced hepatitis in SCID mice. Infect Immun 2009, 77:245-254

45. Anders HJ, Frink M, Linde Y, Banas B, Wornle M, Cohen CD, Vielhauer V, Nelson PJ, Grone HJ, Schlondorff D: CC chemokine ligand 5/RANTES chemokine antagonists aggravate glomerulonephritis despite reduction of glomerular leukocyte infiltration. J Immunol 2003, 170:5658-5666

46. Golden-Mason L, Kelly AM, Doherty DG, Traynor O, McEntee G, Kelly J, Hegarty JE, O'Farrelly C: Hepatic interleuklin 15 (IL-15) expression: implications for local NK/NKT cell homeostasis and development. Clin Exp Immunol 2004, 138:94-101

47. Bekiaris V, Timoshenko O, Hou TZ, Toellner K, Shakib S, Gaspal F, McConnell FM, Parnell SM, Withers D, Buckley CD, Sweet C, Yokoyama WM, Anderson G, Lane PJ: Ly49H+ NK cells migrate to and protect splenic white pulp stroma from murine cytomegalovirus infection. J Immunol 2008, 180:6768-6776

48. Degli-Esposti MA, Smyth MJ: Close encounters of different kinds: dendritic cells and NK cells take centre stage. Nat Rev Immunol 2005, 5:112-124

49. Kalinski P, Moser M: Consensual immunity: success-driven development of T-helper-1 and T-helper-2 responses. Nat Rev Immunol 2005, 5:251-260

50. Kang SJ, Liang HE, Reizis B, Locksley RM: Regulation of hierarchical clustering and activation of innate immune cells by dendritic cells. Immunity 2008, 29:819-833

51. Moretta L, Ferlazzo G, Bottino C, Vitale M, Pende D, Mingari MC Moretta A: Effector and regulatory events during natural killer-dendritic cell interactions. Immunol Rev 2006, 214:219-228

52. Newman KC, Riley EM: Whatever turns you on: accessory-cell-dependent activation of NK cells by pathogens. Nat Rev Immunol 2007, 7:279-291 